\title{
The Ministry of Defence "core meal" offer: changes in compliance with the Armed Forces Food Based Standards between 2013 and 2018
}

\author{
A.M. Shaw ${ }^{1}$, T. Davey ${ }^{1}$ and J.L. Fallowfield ${ }^{1}$ \\ ${ }_{1}^{1}$ Institute of Naval Medicine, Alverstoke, Gosport, PO12 2DL, UK.
}

In 2013 the Institute of Naval Medicine developed the Armed Forces Food Based Standards (AFFBS) ${ }^{(1)}$. The standards, which have been endorsed by Public Health England, advise contract caterers in the provision of foods, meals and menus using ingredients from the different food groups ${ }^{(2)}$. The AFFBS ultimately aim to improve the healthfulness (i.e. conducive to good health) of the core meal offer in Armed Forces (AF) dining facilities by promoting healthier options and restricting the provision of less healthy options.

The aim of the present study was to evaluate the food catering provision of the Ministry of Defence's "core meal" offer in a sample of AF establishments before and after the implementation of the AFFBS.

A representative convenience sample of eleven AF establishments ( $n 4$ British Army, $n 3$ Royal Air Force, $n 3$ Royal Navy, $n 1$ Tri-Service) were selected to participate in the study. The 28-day menu cycles from the incumbent contract caterers for the planned core meal offer for each establishment in 2013 and 2018 were assessed against the AFFBS.

In 2013, the menus analysed complied with three of the fourteen AFFBS. In 2018, the menus analysed complied with nine of the fourteen AFFBS. Of the five AFFBS with which the 2018 contract caterer core provision menus did not fully comply, the proportion of menus which did not comply with the standards was lower in 2018 compared with 2013 (Table 1).

\begin{tabular}{|c|c|c|c|}
\hline AFFBS & Measure & 2013 & 2018 \\
\hline 4 & Range in percentage of starchy food choices at lunch and the evening meal, across the menu cycle, that were cooked in fat or oil & $42-68 \%$ & $29-38 \%$ \\
\hline 8 & Range in percentage of main course options, across the menu cycle, that contained pastry & $4-16 \%$ & $2-8 \%$ \\
\hline \multirow[t]{2}{*}{11} & Range in percentage of main course options at lunch, across the menu cycle, that contained processed meat products & $13-52 \%$ & $10-22 \%$ \\
\hline & Range in percentage of main course options at the evening meal, across the menu cycle, that contained processed meat products & $0-34 \%$ & $6-15 \%$ \\
\hline 12 & $\begin{array}{l}\text { Percentage of establishments providing at least one vegetarian main course option per day which contained either eggs, beans, peas, } \\
\text { lentils or vegetable-based sources of protein }\end{array}$ & $0 \%$ & $18 \%$ \\
\hline 13 & Percentage of establishments providing at least $50 \%$ of dessert options at the evening meal that were based on fruit & $55 \%$ & $73 \%$ \\
\hline
\end{tabular}

In conclusion, the contract caterer menus describing the planned provision for the core meal were more healthful in 2018 compared with 2013. However, the menus analysed in 2018 were still not fully compliant with the AFFBS. Thus, further improvements need to be made by the contract caterers to improve the healthfulness of the core meal offer in order to be fully compliant with the minimum standards provided by the AFFBS.

1. Shaw AM \& Fallowfield JL (2013) Institute of Naval Medicine Report 2013.036. INM, Gosport, UK.

2. MOD (2016) Joint Service Publication 456 Defence Catering Manual. MOD, UK.

(C) Crown Copyright (MOD) 2018. 